\title{
A MODALIDADE VOLITIVA NO DISCURSO DE AUTOAJUDA RELIGIOSO DO PADRE REGINALDO MANZOTTI
}

\section{THE VOLITIVE MODALITY IN THE RELIGIOUS SELF-HELP DISCOURSE OF FATHER REGINALDO MANZOTTI}

André Silva Oliveira ${ }^{1}$ Universidade Federal do Rio Grande do Norte (UFRN)

\section{RESUMO}

Este artigo tem por objetivo descrever e analisar o condicionamento dos aspectos pragmáticos sobre os aspectos semânticos na instauração da modalidade volitiva no discurso de autoajuda religioso. Para isso, tomamos por base a perspectiva do funcionalismo linguístico, com base em Dik (1989) e Hengeveld (2004), que trabalha com o uso efetivo da língua e a integração da pragmática na descrição dos fenômenos linguísticos. Desse modo, selecionamos quatro obras do Padre Reginaldo Manzotti inseridas no domínio do discurso de autoajuda religioso: Batalha espiritual: entre anjos e demônios (2017), Combate espiritual: no dia a dia (2018), O Poder Oculto (2019) e As muralhas vão cair: como fazer um Cerco de Jericó em sua vida (2020). Após a análise das obras, verificamos que o grau de comprometimento do falante no que tange à expressão de volição (extremo, alto, médio, baixo e muito baixo) condiciona tanto os valores modais volitivos (desideração, optação, intenção, exortação e nolição) quanto a natureza do enunciado modalizado (disposicional, reportativa, expressiva e apreciativa).

PALAVRAS-CHAVES: Modalidade; Volitividade; Discurso de Autoajuda.

\section{ABSTRACT}

This article aims to describe and analyse the conditioning of the pragmatic aspects on the semantic aspects in the establishment of the volitive modality in the discourse of religious selfhelp. For this, we take as a base the perspective of linguistic functionalism based on Dik (1989) and Hengeveld (2004) that works with the effective use of language and the integration of pragmatics in the description of linguistic phenomena. In this way, we selected four works by Father Reginaldo Manzotti inserted in the domain of religious self-help discourse: Batalha espiritual: entre anjos e demônios (2017), Combate espiritual: no dia a dia (2018), O Poder Oculto (2019) and As muralhas vão cair: como fazer um Cerco de Jericó em sua vida (2020). After analysing the works, we verified that the degree of commitment of the speaker with respect to the expression of volition (extreme, high, medium, low, and very low) condition both the volitional modal values (desire, will, intention, exhortation, and non-volition) and the nature of the modalized statement (dispositional, reportative, expressive, and appreciative).

KEYWORDS: Modality; Volitivity; Self-help Speech.

\section{INTRODUÇÃO}

Adotamos, neste artigo, a perspectiva funcionalista de descrição e análise linguística, com base em Dik (1989), Hengeveld (2004), Pezatti (2011), Furtado da Cunha (2011) e Neves (2018),

\footnotetext{
${ }_{1}$ Professor Assistente de Língua Espanhola da Faculdade de Engenharia, Letras e Ciências Sociais do Seridó da Universidade Federal do Rio Grande do Norte (FELCS/UFRN) - Campus Currais Novos. Contato: andrethtzn@gmail.com
} 
que considera, como um dos fatores essenciais para a análise dos fenômenos linguísticos, a inserção da pragmática como condicionadora e modeladora das representações semânticas e da estruturação morfossintática das unidades linguísticas no discurso. Com base nisso, objetivamos descrever e analisar o condicionamento dos aspectos semânticos em detrimento dos aspectos pragmáticos (fatores semântico-pragmáticos) na instauração da modalidade volitiva no discurso de autoajuda religioso, especificamente, os quatro livros escritos sob a autoria do Padre Reginaldo Manzotti, a saber: Batalha espiritual: entre anjos e demônios (2017), Combate espiritual: no dia a dia (2018), O Poder Oculto (2019) e As muralhas vão cair: como fazer um Cerco de Jericó em sua vida (2020).

Para esta pesquisa, a escolha da literatura religiosa de autoajuda deve-se, conforme Oliveira (2017), Oliveira e Prata (2018a, 2018b) e Oliveira (2019), a possibilidade de instauração de conteúdos modais volitivos referentes à manifestação de desejos, vontades e intenções e que pudessem ser instauradas pelo autor dos livros (Padre Manzotti) no que tangem ao que ele entende por desejável ou indesejável, como forma de recomendação, conselho e admoestação para o seu público leitor, em sua maioria, os fiéis católicos e/ou aqueles que tenham algum tipo de interesse no conteúdo que é veiculado em seus livros. Ponderamos que a categoria modalidade, que se refere aos posicionamentos do falante perante o que é dito, possa funcionar como uma estratégia argumentativa, em que o falante busca modificar as informações pragmáticas de seu(s) ouvinte(s). Nesse sentido, parece-nos salutar que discorramos, especificamente, acerca da modalidade volitiva que, segundo Hengeveld (2004), está relacionada ao que é (in)desejável (eixo da volição).

No intuito de descrevermos e analisarmos a modalidade volitiva no discurso de autoajuda religioso, dividimos este trabalho em quatro seções: na primeira parte, discorremos sobre os pressupostos básicos da perspectiva funcionalista de análise linguística; na sequência, abordamos acerca das características principais da modalidade volitiva; posteriormente, expomos os aspectos metodológicos, bem como a caracterização do córpus e a delimitação das categorias de análise; em seguida, dissertamos acerca dos resultados e discussões sobre o condicionamento das aspectos semânticos em vista dos aspectos pragmáticos com base no engendramento da modalidade volitiva nos livros do Padre Reginaldo Manzotti. Por fim, passamos para as considerações finais.

\section{$1 \mathrm{O}$ funcionalismo linguístico}

Segundo Neves (2018), o que se entende por funcionalismo linguístico, na verdade, tratase de um conjunto de modelos funcionalistas (para esta pesquisa, será adotado o modelo de linha holandesa) ${ }^{2}$ que concebem a língua como um instrumento de interação social (visão teleológica da linguagem). Conforme a autora, pode-se ainda dizer que o funcionalismo linguístico se refere a uma teoria de organização gramatical das línguas naturais, em que se pretende integrar a gramática a uma teoria global de interação social. Desse modo, a autora acrescenta que a linguagem passa a ser vista como um sistema de modos de expressão plena dos propósitos comunicativos dos usuários de uma língua natural. Nesse sentido, a língua (a gramática de uma língua) não pode ser compreendida como um sistema autônomo, mas como um sistema maleável, sujeito às pressões de uso, cujo parâmetro de referenciação são os aspectos cognitivos e comunicativos, o processamento mental (experiencialista), a interação social e cultural, a mudança e variação das unidades linguísticas, as diferentes formas de aquisição da linguagem, etc.

Assim, de acordo com Furtado da Cunha (2011), a perspectiva funcionalista busca explicar a língua com base nos mais diferentes contextos de produção linguística e na situação extralinguística. Assim sendo, o funcionalismo concebe que a sintaxe das línguas naturais é uma estrutura que está em constante mutação em decorrência das oscilações e mudanças do discurso, moldando-se, portanto, com base nas estratégias e condicionantes da interação verbal. Dessa

${ }^{2}$ O modelo de interação verbal proposto por Dik (1989) e a tipologia das modalidades de Hengeveld (2004). 
forma, segundo a autora, a sintaxe tem a forma que tem em virtude das diferentes estratégias de organização da informação que é veiculada pelos falantes no discurso, ou seja, no momento do uso efetivo da língua.

Nas palavras de Pezatti (2011), a perspectiva funcionalista trabalha com bases explanatórias em que se prioriza a função que as unidades linguísticas exercem no contexto discursivo. Desse modo, segundo a autora, a linguagem é vista como uma ferramenta, em que as formas vão se adaptando às funções que exercem no discurso (uso efetivo da língua) e, dessa forma, as estruturas linguísticas podem ser apenas explicadas com base nas suas funções, que são, em última análise, de natureza comunicativa. Portanto, o princípio de toda explicação linguística, ainda de acordo com a autora, deve ser buscado na relação entre a linguagem e o uso e/ou entre a linguagem e o contexto social, o que torna obrigatório, na perspectiva funcionalista, que as explicações dos fenômenos linguísticos sejam baseadas no contexto sócio-interacional que contraem os participantes da interação (falante e ouvinte) e a sua pressuposta informação pragmática.

Conforme Dik (1989), é na interação verbal entre os participantes do discurso que ocorre uma forma de atividade cooperativa, que, por sua vez, vai se estruturando em termos de regras sociais, normas de conduta e convenções. Nesse sentido, o autor defende que um dos postulados máximos do funcionalismo linguístico consiste em considerar que as regras propriamente linguísticas devem ser avaliadas como instrumentais e, por isso, relacionadas aos objetivos comunicativos dos participantes da interação. Dessa forma, para o autor, o compromisso principal do enfoque funcionalista é o de descrever a linguagem como um requisito pragmático de interação verbal e não como um fim em si mesma.

$\mathrm{Na}$ perspectiva funcionalista, portanto, constatamos, com base em Dik (1989), que a pragmática representa o componente mais abrangente, no qual deve ser estudada a semântica e a sintaxe; a sintaxe é dependente da semântica; que, por sua vez, é dependente da pragmática. Por isso, para o autor, a interação social entre os participantes deve ser entendida como uma atividade estruturada e governada por regras, normas e convenções, além de ser cooperativa, uma vez que é preciso que haja, pelo menos, dois participantes para que a interação verbal seja levada a cabo. Desse modo, conforme Dik (1989), o falante (Padre Reginaldo Manzotti) serve-se das unidades linguísticas (modalizadores volitivos) para expressar seus pensamentos e ideias que, por sua vez, serão organizados, no encadeamento discursivo, com base em regras e princípios que irão determinar sua formação (expressão do que é desejável ou indesejável).

Para Dik (1989), essas regras, sob a ótica da perspectiva funcionalista, envolvem dois sistemas que são reforçados pelas convenções sociais, são eles: (i) as regras que regem a organização das unidades linguísticas, ou seja, regras semânticas, sintáticas, morfológicas e fonológicas; e (ii) regras que governam o funcionamento das expressões linguísticas tendo em vista os padrões da interação verbal, isto é, as regras pragmáticas. Portanto, segundo o autor, o falante (Padre Reginaldo Manzotti) organiza as expressões linguísticas (modais volitivos) conforme a avaliação que é feita com base nas informações pragmáticas de seu ouvinte (os leitores). Nesse sentido, de acordo com Dik (1989), o objetivo do falante é fazer com que o ouvinte concorde com as suas ideias, efetuando, assim, uma mudança na informação pragmática deste, partindo de um conjunto de conhecimentos, crenças, desejos, opiniões, sentimentos, normas, etc., que estão disponíveis aos participantes no momento da interação.

Por isso, ponderamos que a instauração da modalidade volitiva, no discurso religioso de autoajuda, dê-se tanto com base no conjunto de crenças e conhecimentos compartilhados entre o autor do livro e os leitores quanto nos propósitos comunicativos daquele. A partir disso, o falante (Padre Reginaldo Manzotti) irá articular as expressões linguísticas modalizadoras volitivas considerando os aspectos pragmáticos (interação com o público leitor); que, por seu lado, irão condicionar as designações semânticas dessas expressões linguísticas na construção discursiva.

$\mathrm{Na}$ seção seguinte, discorreremos acerca da modalidade volitiva, que, segundo Hengeveld (2004), está relacionada ao que é (in)desejável. Desse modo, exporemos, com base em alguns 
teóricos, os estudos relativos à volição no campo da linguagem. Para isso, abordaremos sobre os aspectos de ordem semântica que particularizam os conteúdos modais volitivos frente aos demais tipos de subcategorias modais, tais como as modalidades deôntica, epistêmica, facultativa, avaliativa, evidencial, etc.

\section{A modalidade volitiva}

Em Hengeveld (2004), a modalidade volitiva é descrita e analisada com base no domínio semântico, que diz respeito à avaliação que se faz do enunciado modalizado; e na orientação modal, que está relacionada à perspectiva em que é qualificada a modalidade. Nesse sentido, a modalidade volitiva, em relação ao domínio semântico, diz respeito ao que é desejável ou indesejável. No que se refere à orientação modal, ela pode estar orientada para: (i) o Participante, quando um dado participante manifesta o desejo de realizar um evento (nível do predicado); (ii) o Evento, quando o falante reporta a necessidade de realização de um evento, mas sem a apreciação subjetiva desse falante (nível da predicação); e (iii) a Proposição, quando diz respeito aos desejos pessoais do falante relativos a um mundo imaginário/fictício (nível da proposição).

De acordo com Casimiro (2007), os estudos relativos ao desejo e à volição são bastante recorrentes nas disciplinas das Ciências Humanas, como a Psicologia e a Linguística, por exemplo. Especificamente, na seara linguística, os estudos relativos ao que é desejável estão relacionados à categoria modalidade volitiva. Conforme o autor, ainda que haja um campo modal específico que situe os desejos e as vontades do falante, a volição se apresenta, em algumas tipologias que se propõem a delimitar e a definir a modalidade, como algo impreciso e de caráter difuso, pois: (i) ora se comporta como um subtipo modal específico; (ii) ora se apresenta como um subtipo modal deôntico, que é relativo às regras e às normas de conduta; e (iii) ora é definida como um tipo de categoria linguística superior a modalidade, a Volitividade (elemento do desejo). De acordo com o autor, isso se deve à vasta gama de valores semânticos modais que podem aparecer associados à volição, tais como a vontade, o desejo, a intenção, a esperança, a promessa, a predição, etc., que, por sua vez, podem representar no fundo uma necessidade deôntica.

No entanto, Oliveira (2017) pondera que a modalidade volitiva tem um comportamento distinto perante os demais subtipos modais, situando-a, designadamente, no eixo da volição, e delimitando-a como o subtipo modal relativo ao que é desejável ou indesejável da parte do falante ou do participante expresso pelo predicado. Assim sendo, a modalidade volitiva pode estar relacionada a eventos relativos a um mundo fictício/imaginário ou ao mundo real, bem como estar relacionada à concretização de eventos controlados pelo falante e/ou pelo ouvinte. Desse modo, o autor especifica quatro valores modais para a modalidade volitiva, são eles: (i) a desideração, volição irrealizável do ponto de vista factual; (ii) a optação, volição realizável, mas dependente de fatores externos; (iii) a intenção, volição realizável da perspectiva do falante, cujo controle de realização do estado-de-coisas depende apenas do falante; ${ }^{3}$ e (iv) a exortação, volição realizável da perspectiva do ouvinte, cujo controle de realização do estado-de-coisas depende, exclusivamente, do ouvinte. Com base nesses valores, o autor delimita que a modalidade volitiva pode ser: (i) de caráter acional, quando requer a concretização de um evento controlado (intenção e exortação); ou (ii) de caráter mental, quando se expressa a possibilidade de concretização de um evento não-controlado (desideração e optação).

Para Oliveira e Prata (2018a), no campo acional, a modalidade volitiva é instaurada por uma fonte volitiva (origem da volição); que, por sua vez, deseja que um dado evento seja realizado (elemento desejado); que, por seu lado, recai sobre um alvo volitivo (sobre quem recai a volição) que ficará a cargo de concretizar o evento volicionado pela fonte. A partir dessas

\footnotetext{
3 Para esta pesquisa, entendemos que esse "falante" pode ser tanto o sujeito enunciador, ou seja, aquele que produz o discurso (o Padre Reginaldo Manzotti que manifesta as suas intenções pessoais); quanto um terceiro-reportado que é introjetado pelo sujeito enunciador no discurso (o Padre Reginaldo Manzotti que reporta as intenções de terceiros em realizar um dado evento).
} 
considerações, os autores especificam diferentes tipos de fonte volitiva, a saber: Enunciador, quando se trata do próprio falante; Indivíduo, quando advém de uma pessoa em particular que é reportada pelo falante; Instituição, quando advém de um grupo institucional específico que é reportado pelo falante; e Domínio Comum, quando advém da coletividade, ou seja, refere-se a um evento desejado de âmbito coletivo. Em relação ao alvo volitivo, os autores nomeiam seis tipos específicos: Enunciador, quando recai ao falante a concretização do evento desejado; Indivíduo, quando recai sobre um sujeito em particular a concretização do evento volicionado; Instituição, quando recai sobre um grupo institucional a realização do evento almejado; Domínio Comum, quando recai sobre a coletividade a concretização do evento ambicionado; Coenunciador, quando recai diretamente sobre o ouvinte a quem o falante se direciona para a realização do evento desejado; e Inexistente, quando não há a especificação de um alvo que deverá executar a ação desejada.

Em Oliveira (2019), constatamos que os tipos de enunciados modalizados volitivamente podem ser de duas diferentes naturezas: (i) reportativa, quando o falante declara o que parece desejável a um sujeito que é reportado em seu discurso, não se comprometendo, dessa forma, com o evento volicionado, pois o que é desejado como sendo bom e agradável é oriundo de um outro sujeito que não a sua pessoa, como exemplo: Daqui em diante, nos pautaremos pela vontade soberana daqueles brasileiros [...] que desejam conquistar, pelo mérito, bons empregos e sustentar com dignidade suas familias (OLIVEIRA, 2019, p. 1222); e (ii) apreciativa, quando o falante faz uma apreciação pessoal acerca do evento sobre o qual incide a volição, colocando-se, portanto, como fonte volitiva e comprometendo-se com o evento desejado, haja vista que é ele quem avalia o evento como sendo bom e agradável, como no exemplo: Pretendo partilhar o poder, de forma progressiva, responsável e consciente, de Brasilia para o Brasil; do Poder Central para Estados e Municípios (OLIVEIRA, 2019, p. 1220).

Tomando por base a orientação modal de Hengeveld (2004), propomos fazer uma readequação da natureza modal volitiva proposta por Oliveira (2019). Assim sendo, a natureza do enunciado modalizado pode ser: (i) disposicional, quando o falante expressa seu desejo de concretizar o evento desejado, em que o modalizador volitivo tem escopo de atuação sobre um predicado; (ii) reportativa, quando o falante expressa o desejo do sujeito introjetado no discurso em realizar o evento desejado, em que o modalizador volitivo também tem escopo de atuação sobre um predicado/predicação; (iii) expressiva, quando o falante manifesta o desejo de concretização de eventos, mas sem serem avaliados por ele de maneira subjetiva, em que o modalizador volitivo tem escopo de atuação sobre uma predicação; e (iv) apreciativa, quando o falante faz apreciações pessoais acerca de eventos por ele desejados relativos a um mundo imaginário/fictício, em que o modalizador volitivo tem escopo de atuação sobre uma proposição.

Para Oliveira e Prata (2018b), que estudaram a volição em língua espanhola, a modalidade volitiva pode ser expressa por meio de distintas formas de expressão linguística, a saber: (i) auxiliares modais (querer+infinitivo, desear+infinitivo, anbelar+infinitivo, pretender+infinitivo, necesitar+infinitivo, pensar+infinitivo, etc.), verbos de significação plena (querer, desear, anhelar, preferir, etc.), substantivos (deseo, voluntad, anhelo, intención, etc.), adjetivos em função predicativa (es necesario, es deseable, es preferible, es bueno, etc.) e construções modalizadoras com verbos suporte (tengo ganas de, tengo la voluntad de, hacer votos, tengo la intención de, etc.).

Como podemos constatar, os avanços nos estudos acerca da modalidade volitiva puderam situá-la como um subtipo modal específico, com eixo modal definido (eixo da volição), valores modais delimitados (desideração, optação, intenção e exortação), diferentes tipos de natureza modal (reportativa e apreciativa) e meios de expressão linguística (auxiliares modais, verbos de significação plena, substantivos, adjetivos em função predicativa e construções modalizadoras). No entanto, acreditamos que seja necessário que se analise o condicionamento dos aspectos semânticos (aspectos estes já estudados em trabalhos anteriores, como os citados nesta pesquisa) perante os aspectos pragmáticos. Ponderamos também que esse condicionamento possa ter reflexo sobre a forma como as designações semânticas dos conteúdos modais volitivos possam 
ser engendrados no discurso em vista dos aspectos pragmáticos, que, por sua vez, são relativos à interação entre o falante (autor do livro) e o ouvinte (os leitores do livro).

$\mathrm{Na}$ seção seguinte, iremos especificar os aspectos metodológicos desta pesquisa, no que tange à delimitação do córpus, à designação das categorias de análise e à apreciação da literatura de autoajuda.

\section{Metodologia}

No intuito de descrevermos e analisarmos a modalidade volitiva no discurso de autoajuda religioso e, dessa forma, explicitarmos o condicionamento dos aspectos semânticos em decorrência dos aspectos pragmáticos, optamos pelos livros publicados sob a autoria do Padre Reginaldo Manzotti, a saber: (1) Padre Reginaldo Manzotti. Batalha espiritual: entre anjos e demônios. Rio de Janeiro: Editora Petra, 2017. 176p.; (2) Padre Reginaldo Manzotti. Combate espiritual: no dia a dia. Rio de Janeiro: Editora Petra, 2018. 200 p.; (3) Padre Reginaldo Manzotti. O Poder Oculto. Rio de Janeiro: Petra, 2019. 176 p.; e (4) Padre Reginaldo Manzotti. As muralhas vão cair: como fazer um Cerco de Jericó em sua vida. Rio de Janeiro: Editora Petra, 2020. 176p.

A escolha pelas obras de autoajuda se deve, especificamente, pois a este tipo de gênero, conforme Gasparini-Bastos e Brunelli (2019), ter se mostrado um terreno fértil para a manifestação da categoria modalidade, em que o autor do livro (falante - Padre Reginaldo Manzotti) pode manifestar suas crenças e conhecimentos de mundo e, com base neles, regular normas e regras de conduta para os seus leitores a partir do que ele avalia como sendo (in)desejável (modalidade volitiva) para si e para os demais (os seus leitores). Ainda segundo as autoras, a literatura de autoajuda tem tido, nos últimos anos, um crescimento exponencial no mercado editorial, alcançando públicos cada vez mais específicos, haja vista que é possível encontrarmos obras de autoajuda direcionadas para adolescentes, idosos, mulheres, enfermos, mães e, designadamente, para fiéis adeptos de algum grupo religioso (para esta pesquisa, os fiéis católicos).

De acordo com Bessa (2008), o gênero discurso de autoajuda se refere a uma miscelânia de outros tipos de gênero, compondo-se de vários tipos textuais, como narrativas, descrições, conselhos, ordens, desejos (modalidade volitiva), receituários, etc. Nesse sentido, o discurso de autoajuda tem como especificidade trazer ao público leitor reconforto, esperança, autoconfronto e resolução de problemas. No que tange à literatura de autoajuda religiosa, a autora especifica que as obras buscam se apropriar de discursos científicos para validar suas crenças e opiniões acerca de condutas e regras de cunho moral, trazendo não apenas instruções espirituais para o seu público leitor, como também preceitos morais, que serão avaliados como sendo desejáveis ou indesejáveis (eixo da volição).

Sabendo-se que o discurso de autoajuda religioso pode propiciar a instauração de modalidade volitiva, selecionamos algumas categorias de análise de ordem pragmática e semântica que possibilitem a descrição e análise da qualificação modal volitiva neste tipo de discurso. Para isso, foram delimitadas as seguintes categorias de análise: (i) o grau de comprometimento do falante em relação à volição instaurada, que pode ser extremo (centrado na pessoa do falante ${ }^{4}$ ), alto (centrado na pessoa do falante e do ouvinte ${ }^{5}$ ), médio (centrado na pessoa do ouvinte), baixo (centrado no sujeito ${ }^{6}$ que é reportado no discurso) e muito baixo (sem a especificação de um sujeito); (ii) os valores modais volitivos, que podem ser desideração, optação, intenção, exortação e

\footnotetext{
${ }^{4}$ Para esta pesquisa, entender a pessoa do "falante" como sendo o Padre Reginaldo Manzotti.

5 Para esta pesquisa, entender a pessoa do "ouvinte" como os leitores dos livros de autoajuda do Padre Reginaldo Manzotti.

6 Para esta pesquisa, entender a pessoa do "sujeito" como um terceiro-reportado que é introjetado no discurso do Padre Reginaldo Manzotti.
} 
nolição; ${ }^{7}$ e (iii) a natureza do enunciado modalizado, que pode ser disposicional, reportativa, expressiva e apreciativa.

Para esta pesquisa, entendemos o grau de comprometimento do falante como uma categoria de ordem pragmática, haja vista que pode haver uma relação entre a volição instaurada no discurso e o envolvimento do falante/ouvinte com aquilo que é desejado. Nesse sentido, o falante pode criar diferentes projeções em torno da volição instaurada, podendo, no discurso, evocar: a singularidade da sua pessoa; diluí-la em meio a coletividade (o que inclui o ouvinte); centrá-la apenas no ouvinte; projetá-la por meio de um sujeito introjetado no discurso (terceiro-reportado); ou não especificar a existência de um indivíduo sobre quem parte ou recai a volição instaurada. Por sua vez, a natureza do enunciado modalizado é vista como uma categoria de ordem semântica, pois está relacionada às possíveis designações semânticas que a volição instaurada é construída no discurso, cuja qualificação da atitude modal pode estar voltada para sujeitos e/ou eventos. Assim sendo, quando relativa a sujeitos, entende-se a volição expressa como sendo de caráter acional (deseja-se realizar um evento, ou seja, necessidade volitiva). Por sua vez, quando voltada para eventos, geralmente a volição se reveste de um caráter mental (manifesta-se a probabilidade de que um dado evento venha a se concretizar, ou seja, possibilidade volitiva).

Com base nesses critérios, a pesquisa caracteriza-se tanto foi pensada tanto em qualitativa, haja vista que a categoria modalidade volitiva será descrita e analisada com base no que é prédisposto na seara linguística de perspectiva funcionalista; quanto quantitativa, em virtude dos dados serem analisados com base em um programa estatístico para a geração das frequências e das inter-relações entre as categorias de análise, no caso, o Statistical Package for the Social Sciences (SPSS) - versão 22 para o Windows.

Tendo em vista a abordagem da categorização do córpus e da apreciação das categorias de análise, passar-se-á, na seção seguinte, para os resultados e as discussões sobre a instauração da modalidade volitiva no discurso de autoajuda religioso do Padre Reginaldo Manzotti.

\section{Resultados e discussão}

Após a leitura dos livros do Padre Reginaldo Manzotti que compuseram o universo desta pesquisa, detectamos 278 modalizações volitivas, em que essas modalizações foram descritas e analisadas com base nas categorias de análise selecionadas para a qualificação da modalidade volitiva no discurso de autoajuda religioso. Com o auxílio do programa estatístico Statistical Package for the Social Sciences (SPSS), em que fizemos a rodagem dos dados e a inter-relação entre as categorias de análise de ordem pragmática e semântica, verificamos, por meio do valor do Quiquadrado $(\leq 0,05)$, que o grau de comprometimento do falante em relação à volição expressa (aspecto pragmático) condiciona tanto os valores modais volitivos quanto a natureza do enunciado modalizado (aspectos semânticos).

De acordo com Guy e Zilles (2007), o valor do Qui-quadrado é relevante quando se pretende calcular a probabilidade de que uma dada hipótese seja verdadeira. ${ }^{8}$ Conforme os autores, se o resultado da inter-relação entre duas categorias de análise for $\leq 0,05$ (valor comumente aceito no que tangem aos estudos estatísticos), isso quer dizer que elas estão interrelacionadas, ou seja, as variações de uso de uma categoria de análise condiciona as variações no uso da outra categoria.

No que se refere à inter-relação entre o grau de comprometimento do falante e os valores modais volitivos, vejamos a Tabela 1:

\footnotetext{
${ }^{7}$ Os valores modais de desideração, optação, intenção e exortação foram baseados em Oliveira (2017). Para além desses valores, acreditamos que a negação de volição (nolição) também poderia influenciar os possíveis efeitos de sentido pretendidos pelo autor dos livros de autoajuda em sua construção discursiva e argumentativa.

8 Para rejeitar a hipótese nula, fixou-se em 0,05 o nível de rejeição da hipótese de nulidade. Por isso, foram considerados como condicionamento entre as categorias de análise apenas os casos com valor p inferior a 0,05.
} 
Tabela 1: A inter-relação entre o grau de comprometimento do falante e os valores modais volitivos $^{9}$

\begin{tabular}{|c|c|c|c|c|c|c|}
\hline \multirow{2}{*}{$\begin{array}{c}\text { Grau de } \\
\text { comprometimento }\end{array}$} & \multicolumn{5}{|c|}{ Valores modais volitivos } & \multirow{2}{*}{ Total } \\
\cline { 2 - 6 } & Intenção & Optação & Desideração & Exortação & Nolição & \\
\hline Baixo & $59(21,2 \%)$ & $63(22,7 \%)$ & $00(0,0 \%)$ & $01(0,4 \%)$ & $20(7,2 \%)$ & $143(51,4 \%)$ \\
\hline Alto & $25(9 \%)$ & $15(5,4 \%)$ & $02(0,7 \%)$ & $00(0,0 \%)$ & $05(1,8 \%)$ & $47(16,9 \%)$ \\
\hline Extremo & $23(8,3 \%)$ & $01(0,4 \%)$ & $02(0,7 \%)$ & $01(0,4 \%)$ & $09(3,2 \%)$ & $36(12,9 \%)$ \\
\hline Muito baixo & $07(2,5 \%)$ & $22(7,9 \%)$ & $00(0,0 \%)$ & $00(0,0 \%)$ & $03(1,1 \%)$ & $32(11,5 \%)$ \\
\hline Médio & $12(4,3 \%)$ & $07(2,5 \%)$ & $00(0,0 \%)$ & $00(0,0 \%)$ & $01(0,4 \%)$ & $20(7,2 \%)$ \\
\hline Total & $126(45,3 \%)$ & $108(38,8 \%)$ & $04(1,4 \%)$ & $02(0,7 \%)$ & $38(13,7 \%)$ & $278(100 \%)$ \\
\hline
\end{tabular}

Fonte: Elaborado pelo autor com base nos dados do SPSS

Considerando os dados da Tabela 1, atestamos que o grau de comprometimento do falante em relação ao valor modal instaurado tende a ser baixo (51,4\%), em que a volição expressa está centrada no sujeito reportado no discurso, escolhendo para isso os valores modais de optação $(22,7 \%)$ e intenção $(21,2 \%)$. Os casos de baixo comprometimento do falante (Padre Reginaldo Manzotti) em relação ao valor modal de intenção deve-se ao fato de o sacerdote se referir à volição de terceiros em realizar um dado evento, ou seja, o padre católico introjeta, em seu discurso, um terceiro-reportado que deseja realizar algo (geralmente diz respeito ao que é volicionado pela divindade). Por seu lado, os casos de tipo extremo (8,3\%) estão relacionados ao que o Padre Reginaldo Manzotti deseja concretizar. Vejamos as ocorrências (1) e (2):

(1) Segundo sua própria avaliação, ela quer que os filhos tenham o melhor, o que não é errado, mas acaba cedendo à tentação de "manter as aparências" a qualquer custo (COMBATE ESPIRITUAL: NO DIA A DLA).

(2) Façamos, portanto, uso daquilo que o Senhor quer dar - e não me refiro a bens materiais, mas à forç, à paz. è serenidade para carregarmos a cruz. de cada dia (COMBATE ESPIRITUAL: NO DLA A DLA).

Em (1), a modalidade volitiva é instaurada por meio do verbo de significação plena querer, em que o falante (Padre Manzotti) reporta a volição do sujeito introjetado no discurso, ela, que, por sua vez, expressa o desejo de que seus filhos tenham tudo do melhor. Por seu lado, em (2), a modalidade volitiva é instaurada por meio da construção perifrástica querer+infinitivo, em que o falante reporta o desejo da divindade, que consiste em dar a força, paz e serenidade às pessoas que o buscam. Consideramos que, para a modalidade volitiva, haja um baixo grau de comprometimento, em virtude de o falante pretender introjetar a volição de terceiros como forma de modelo daquilo que é bom e agradável e, portanto, deva também ser desejado pelo seu ouvinte (leitor); ou como exemplo daquilo que é ruim e desagradável e, assim, que não deva ser volicionado pelo seu ouvinte (leitor).

De maneira análoga, podemos dizer também que os graus de comprometimento alto $(16,9 \%)$ podem funcionar como modelos de eventos que devam ser desejados pelos ouvintes (leitores). Nesses casos, o falante (Padre Reginaldo Manzotti) projeta a volição centrada na sua pessoa e na pessoa do ouvinte (leitores), como na ocorrência (3), cujo valor modal é de intenção ( $9 \%)$; e na ocorrência (4), em que o valor modal instaurado é de optação $(5,4 \%)$ :

(3) Quando nosso pensamento se eleva a Deus e demonstramos em palavras os sentimentos intimos do nosso coração, quando falamos com Ele como a um amigo próximo e querido que também desejamos ouvir, estamos farendo a oração mental (AS MURALHAS VÃO CAIR: COMO FAZER UM CERCO DE JERICÓ EM SUA VIDA).

\footnotetext{
${ }^{9} \mathrm{O}$ valor do Qui-quadrado foi de 0,00.
} 
(4) Queremos uma vida fácil, com ausência de dor, e por isso nos esquivamos da poda necessária. A provação e a tribulação são lados dolorosos da economia salvifica de Deus (AS MURALHAS VÃO CAIR: COMO FAZER UM CERCO DE JERICÓ EM SUA VIDA).

Em (3), a modalidade volitiva é instaurada por meio da construção perifrástica desejar+infinitivo, em que o falante expressa a volição coletiva (o que é evidenciado pela marca de primeira pessoa do plural, desejamos) de ouvir os desígnios de Deus por meio da oração mental, como se faz quando se direciona a atenção para um amigo. Em (4), a modalidade volitiva é instaurada por meio do verbo de significação plena querer, em que o falante também manifesta a volição coletiva (marcada pela primeira pessoa do plural, queremos) de uma vida fácil, sem dor e que não precise "ser podada". Acreditamos que, nas ocorrências (3) e (4), ao projetar a si mesmo e ao ouvinte, o falante (Padre Reginaldo Manzotti) pretende utilizar-se dos desejos de âmbito coletivo como forma de modelo do que é desejável, como em (3); e do que é indesejável, como em (4), do ponto de vista da fé cristã católica.

Em relação ao grau de comprometimento do tipo extremo $(12,9 \%)$, em que o falante (Padre Reginaldo Manzotti) centra a projeção da volição em torno da singularidade da sua pessoa, verificamos que o valor de modal de intenção $(8,3 \%)$ é o mais recorrente. Nesses casos, pensamos que o falante pretenda servir de modelo daquilo que é desejável ou indesejável, em termos de seguimento da fé e espiritualidade, em razão de sua posição como sacerdote; ou para instigar o ouvinte (leitor) para uma possível mudança de comportamento, como nas ocorrências (5) e (6):

(5) Respeito todas as crenças e procuro destacar sempre aquilo que nos une, e não o que nos separa. Sei também que a doutrina espírita recomenda o amor e a caridade, mas não se alinha em tudo à doutrina cristã. Se livremente escolhemos seguir a Igreja Católica Apostólica Romana, precisamos conhecer os fundamentos da nossa fé e sermos fiéis à doutrina e ao magistério da Igreja fundada por Cristo (COMBATE ESPIRITUAL: NO DIA ADLA).

(6) Neste ponto, quero me dirigir diretamente a quem tem pensamentos suicidas. Perceba, meu filho e minha filha, que essa não é a saída. Deus vai restaurar sua força e sua alegria. Ele nos ama tanto que o preço pago por você, por mim, por todos nós, foi muito alto (COMBATE ESPIRITUAL: NO DLA A DLA).

Em (5), a modalidade volitiva é instaurada por meio da construção perifrástica procurartinfinitivo, em que o falante expressa uma intenção particular (que pode ser evidenciada pelo uso da primeira pessoa do singular, procuro) de respeitar todas as crenças religiosas, buscando sempre destacar os pontos doutrinários que une a todas elas. Ao expressar sua intenção, acreditamos que o falante deseje colocar-se como modelo para o seu ouvinte (leitor), fazendo com que ele busque mudar a sua forma de pensar em relação ao que é desejado pelo autor (Padre Manzotti), em questão: respeitar as diferenças religiosas, se ainda não o faz.

Por sua vez, em (6), a modalidade volitiva é instaurada por meio da construção perifrástica querer+infinitivo, em que o falante expressa a intenção de se direcionar para um público-alvo específico, as pessoas que tenham pensamentos suicidas, buscando chamar a atenção dessas pessoas em particular e admoestando-as de que Deus pode solucionar seus problemas. Ponderamos que, nesses casos específicos, a modalidade volitiva possa ser engendrada no intuito de sinalizar uma atenção particular do falante (Padre Manzotti) para com esse tipo de público específico, revelando sua preocupação para com a situação em que essas pessoas se encontram. Em alguns casos específicos, como em (6), a volição instaurada pode também funcionar como uma marca de polidez e cortesia, como forma de atrair a atenção do auditório (público leitor) em particular. 
No que diz respeito ao grau de comprometimento do falante do tipo muito baixo (11,5\%), verificamos que corresponde ao valor modal de optação $(7,9 \%)$, em que o falante se restringe a expressar a necessidade de concretização de eventos, sejam estes desejáveis ou indesejáveis e, consequentemente, sem a especificação de um sujeito, como nas ocorrências (7) e (8):

(7) Muitas vezes, o mal da inveja se manifesta na tristeza sentida diante do êxito ou do bem-estar de outra pessoa e no desejo incontrolável de se apropriar disso (COMBATE ESPIRITUAL: NO DIA A DIA).

(8) Inspirada por essa passagem bíblica, em que o desejo de se manter em uma relativa zona de conforto se sobressai ao desejo de liberdade, ficou célebre a expressão 'choras as cebolas do Egito' (AS MURALHAS VÃO CAIR: COMO FAZER UM CERCO DE JERICÓ EM SUA VIDA).

Em (7) e (8), o falante emprega o substantivo desejo (Sintagma Nominal, em que o núcleo desse sintagma é recortado por um Sintagma Preposicional) para instaurar a modalidade volitiva, referente, respectivamente, à volição de se apropriar do que o outro conquistou e de se manter em uma zona de conforto. Nesses casos, a volição expressa é relativa a um evento, por isso, sem a especificação de um sujeito, fazendo com a volição expressa sirva como forma de modelo para aquilo que o ouvinte (leitor) deva apreciar como sendo algo bom e agradável ou não. Parafraseando as ocorrências (7) e (8), teríamos: Deseja-se incontrolavelmente se apropriar do bem-estar de outra pessoa e Deseja-se manter em uma relativa zona de conforto.

Por sua vez, em relação ao grau de comprometimento do falante do tipo médio $(7,2 \%)$, sobressai-se o valor modal de intenção (4,3\%), em que o falante dialoga diretamente com seu ouvinte (leitor), buscando levá-lo a uma mudança de comportamento, ao expressar uma intenção (volição) que poderia advir do próprio ouvinte, como nas ocorrências (9) e (10):

(9) De fato, Jesus curou aquele homem. Então, eu lhe pergunto sem rodeios: E você, quer ser curado? (O PODER OCULTO).

(10) Certamente, um olho-d'água, sozinho, não tem o poder de reavivar um deserto, mas muitos deles formam um rio como o Amazonas, o maior do planeta. E quanto a você: quer se transformar também em uma fonte de água abundante? ( $O$ PODER OCULTO).

Em (9) e (10), a modalidade volitiva é instaurada por meio da construção perifrástica querertinfinitivo, em que o falante admoesta o seu ouvinte (leitor) sobre, respectivamente, a intenção (volição) de ser curado por Jesus (divindade) e de se transformar em uma fonte de água abundante.

Desse modo, atestamos que o grau de comprometimento do falante em relação ao valor modal volitivo instaurado tem como propósito apresentar diferentes projeções da volição expressa, ora centrando-a: (i) em um terceiro-reportado (baixo); (ii) no falante e no ouvinte (alto); (iii) apenas no falante (extremo); (iv) na desejabilidade de concretização de um evento (muito baixo); e (v) no ouvinte (baixo), para quem o falante direciona o seu discurso. Dessa forma, a volição manifestada pode produzir diferentes efeitos de sentido no que tange à instauração da modalidade volitiva na construção discursiva.

Em relação à inter-relação entre o grau de comprometimento do falante e a natureza do enunciado modalizado, vejamos a Tabela 2: 
Tabela 2: A inter-relação entre o grau de comprometimento do falante e a natureza do enunciado modalizado $^{10}$

\begin{tabular}{|c|c|c|c|c|c|}
\hline \multirow{2}{*}{$\begin{array}{c}\text { Grau de } \\
\text { comprometimento }\end{array}$} & \multicolumn{3}{|c|}{ Natureza do enunciado modalizado } & \multirow{2}{*}{ Total } \\
\cline { 2 - 5 } & Disposicional & Reportativa & Expressiva & Avaliativa & \\
\hline Baixo & $01(0,4 \%)$ & $142(51,1 \%)$ & $00(0,0 \%)$ & $00(0,0 \%)$ & $143(51,4 \%)$ \\
\hline Alto & $45(16,2 \%)$ & $00(0,0 \%)$ & $00(0,0 \%)$ & $02(0,7 \%)$ & $47(16,9 \%)$ \\
\hline Extremo & $34(12,2 \%)$ & $00(0,0 \%)$ & $00(0,0 \%)$ & $02(0,7 \%)$ & $36(12,9 \%)$ \\
\hline Muito baixo & $00(0,0 \%)$ & $01(0,4 \%)$ & $31(11,2 \%)$ & $00(0,0 \%)$ & $32(11,5 \%)$ \\
\hline Médio & $00(0,0 \%)$ & $20(7,2 \%)$ & $00(0,0 \%)$ & $00(0,0 \%)$ & $20(7,2 \%)$ \\
\hline Total & $80(28,8 \%)$ & $163(58,6 \%)$ & $31(11,2 \%)$ & $04(1,4 \%)$ & $278(100 \%)$ \\
\hline
\end{tabular}

Fonte: Elaborado pelo autor com base nos dados do SPSS

Ao fazermos a inter-relação entre o grau de comprometimento do falante e a natureza do enunciado modalizado, pudemos verificar, por meio dos dados quantitativos, um dos princípios básicos do funcionalismo linguístico: a pragmática como modeladora e condicionadora da semântica. Nesse sentido, ao criar diferentes projeções em torno da volição instaurada, o falante (Padre Reginaldo Manzotti) vai construindo diferentes tipos de enunciadores em seu discurso, ou seja, introjetando distintas vozes que manifestam o desejo de realizar algo ou que expressam a possibilidade de concretização de algum evento. Isso, pois, tem reflexo nas designações semânticas da volição ao ser instaurada no discurso, sendo de caráter acional, quando relativa a sujeitos, o que tem relação com as naturezas modais de tipo disposicional e avaliativa (alto e extremo) e reportativa (baixo); e sendo de caráter mental quando relativa a eventos, o que tem relação com a natureza modal de tipo expressiva (muito baixo).

Considerando os dados expostos na Tabela 2, verificamos que os graus de comprometimento do falante de tipo baixo $(51,4 \%)$ e médio $(7,2 \%)$ correspondem ao enunciado modalizado de natureza reportativa, o que é justificável, se considerarmos que, nesses casos, o falante se restringe a expressar a volição de um terceiro-reportado e do ouvinte (leitor) com quem dialoga. Por sua vez, os graus de comprometimento do falante de tipo alto $(16,9 \%)$ e extremo $(12,9 \%)$ configuram em enunciados modalizados de natureza disposicional, o que se explica em razão de o falante expressar uma volição coletiva ou de cunho pessoal. Por sua parte, o grau de comprometimento do falante de tipo muito baixo (11,5\%) ocorre em enunciados de natureza expressiva, o que é esperado, em virtude de o falante manifestar a (in)desejabilidade de concretização de eventos.

As ocorrências de (11) a (15) ilustram os tipos de natureza do enunciado modalizado em relação ao grau de comprometimento do falante, respectivamente baixo, médio, alto, extremo e muito baixo:

(11) Deus está sempre disposto a nos ajudar em nossas necessidades. Ele sabe que, às vezes, saciamo-nos com porcarias; e, como bom pai, frequentemente nos corrige, uma vez que nos quer nutrir com algo que nos leve ao Cén (BATALHA ESPIRITUAL: ANJOS E DEMÔNIOS).

(12) Você quer fazer um Cerco de Jericó em sua vida? Quer derrubar as muralhas que estão impedindo de ter uma intimidade maior com Deus Pai? Então, a partir deste ponto, aprofunde-se comigo no entendimento da oração do Senhor (AS MURALHAS VÃO CAIR: COMO FAZER UM CERCO DE JERICÓ EM SUA VIDA).

(13) Admitir o erro e "puxar" a responsabilidade para a gente não é fácil. Em geral, preferimos acreditar que "Deus quis assim", o que não é uma boa justificativa. Deus quer que cheguemos n'Ele e nos mostra as pistas, mas as decisões são nossas (O PODER OCULTO).

${ }^{10} \mathrm{O}$ valor do Qui-quadrado foi de 0,00 . 
(14) Este não é um coaching sobre poder da mente, e não pretendo ensinar ninguém a programar o próprio cérebro. O que desejo é que nos programemos para receber e potencializar a graça de Deus (O PODER OCULTO).

(15) Há diferentes razões a explicar por que nossas orações não são respondidas imediatamente. Muitas vezes, elas são tentativas de convencer a Deus a respeito de nossas necessidades, que por sua vez, correspondem tão somente ao desejo de satisfazer instintos egoistas (AS MURALHAS V ÃO CAIR: COMO FAZER UM CERCO DE JERICÓ EM SUA VIDA).

Em (11), a modalidade volitiva é instaurada por meio da construção estar+particípio, que, por sua vez, tem escopo de atuação sobre um verbo performativo ajudar, configurando-se, assim, uma construção modalizadora volitiva, em que o falante (Padre Manzotti) reporta a intenção do sujeito introjetado no discurso (Deus) de ajudar as pessoas em suas necessidades. Por sua vez, em (12), recorre-se à construção perifrástica querer+infinitivo, inserida no discurso por meio de uma pergunta, em que se questiona acerca de um possível desejo (possibilidade volitiva) do ouvinte (leitor) de fazer o Cerco de Jericó.

Em (13), emprega-se à construção perifrástica preferirtinfinitivo, em que o falante (Padre Reginaldo Manzotti) expressa um desejo coletivo, que pode ser evidenciado pela marca de primeira pessoa do plural (preferimos), de acreditar que as coisas sucedem na vida pela simples vontade de Deus. Por seu lado, em (14), a volição é expressa por meio do verbo de significação plena desejar, em que o falante (Padre Reginaldo Manzotti) expressa a sua vontade pessoal (o que pode ser constatado por meio da marca de primeira pessoa do singular, desejo) de que todos possam se programar para receber a graça de Deus. Por fim, em (15), verificamos o uso do substantivo desejo, em que o falante (Padre Reginaldo Manzotti) reporta a volição de concretização de um evento que, por seu lado, consiste na satisfação dos instintos egoístas.

A partir dos resultados obtidos com base na análise quantitativo-qualitativa da modalidade volitiva no discurso de autoajuda religioso, podemos constatar que há um condicionamento do aspecto pragmático (o grau de comprometimento do falante) em relação aos aspectos semânticos (valores modais e natureza do enunciado modalizado) envolvidos na instauração dos conteúdos modais volitivos.

\section{CONSIDERAÇÕES FINAIS}

Neste artigo, procuramos descrever e analisar o condicionamento dos aspectos pragmáticos em relação aos aspectos semânticos na instauração da modalidade volitiva no discurso de autoajuda religioso, valendo-nos do valor do Qui-quadrado $(\leq 0,05)$ como forma de verificar a probabilidade de que uma dada hipótese seja verdadeira. Para isso, estipulamos, com base no que é comumente aceito em termos de dados estatísticos, o valor de 5\% como nível de rejeição da hipótese de nulidade, considerando apenas os casos com valor p inferior a 0,05. Após a rodagem dos dados, atestamos, a partir dos dados fornecidos pelo SPSS, que os valores referentes à inter-relação entre as categorias de análise pragmáticas e semânticas foram inferiores ao valor fixado $(\mathrm{p}<0,05)$.

No que diz respeito à inter-relação entre o grau de comprometimento do falante em relação à expressão da volição e os valores modais volitivos, constatamos que a preferência é de tipo baixo, escolhendo para isso os valores de optação e intenção, em razão de o falante reportar as vontades e intenções de sujeitos que são introjetados em seu discurso, tais como as entidades relativas à crença cristã (Deus, Diabo, Santos, etc.) ou as pessoas de um modo geral. Observamos também certa recorrência de tipo alto, em que o falante expressa as volições de âmbito coletivo, isto é, tanto os seus desejos e vontades pessoais em conjunto com os dos seus ouvintes (leitores), buscando, dessa forma, aproximar-se de seu público leitor.

O grau de comprometimento do falante influenciou também a natureza do enunciado modalizado, em que os de tipo baixo e médio se relacionam aos enunciados modalizados de 
natureza reportativa, considerando que, nesses casos, o falante se limita a expressar a volição de um terceiro-reportado e do ouvinte com quem dialoga em seu discurso. Por sua vez, os de tipo alto e extremo configuram em enunciados modalizados de natureza disposicional, pois o falante manifesta as volições tanto de âmbito coletivo quanto as de cunho pessoal. Por seu turno, as de tipo muito baixo ocorrem em enunciados modalizados de natureza expressiva, já que, para esses casos, o falante se restringe a expressar a (in)desejabilidade de concretização de eventos.

Considerando a importância do estudo sobre a linguagem e seu uso efetivo em contextos reais de produção (base epistemológica da perspectiva funcionalista), acreditamos que o engendramento da modalidade volitiva no discurso de autoajuda religioso possa ainda conter outros elementos de ordem semântica e pragmática, além de outros aspectos linguísticos e extralinguísticos, ainda não contemplados nesta pesquisa, mas que seriam oportunos no que diz respeito aos estudos sobre a modalidade volitiva, tais como: o emprego de metáforas na instauração da volitividade, a polifonia dos discursos, o tipo de ilocução, os tipos de fonte e alvo volitivos, etc.

Por fim, esperamos que as reflexões apresentadas nesta pesquisa possam contribuir, ainda que de maneira modesta, para os estudos relativos ao campo das modalidades e seu uso como recurso discursivo e estratégia argumentativa.

\section{REFERÊNCIAS}

BESSA, Daniela Borja. Literatura de autoajuda cristã: em busca da felicidade ainda na terra e não só para o céu. 2008. 221f. Tese (Doutorado em Ciências da Religião) - Programa de Pós-Graduação em Ciências da Religião, Pontifícia Universidade Católica de São Paulo, 2008.

CASIMIRO, S. Um estudo das modalidades deôntica e volitiva nos discursos do presidente Lula. São José do Rio Preto: 2007, 107f. Dissertação (Mestrado em Estudos Linguísticos) - Instituto de Biociências, Letras e Ciências Exatas, Universidade Estadual Paulista, 2007.

DIK, Simon. The Theory of Functional Gramma: The Structure of the Clause. Dordrecht: Foris Publications, 1989.

FURTADO DA CUNHA, Maria Angélica. Funcionalismo. In: MARTELOTTA, Mario Eduardo (Org.). Manual de linguística. São Paulo: Editora Contexto, 2011.

GASPARINI-BASTOS, Sandra Denise; BRUNELLI, Anna Flora. A coocorrência de elementos modais em obras de autoajuda dirigidas a mulheres. Revista Estudos Linguísticos, v. 48, n. 1, 2019, p. 262-275. Disponível em: <https://revistas.gel.org.br/estudoslinguisticos/article/view/2280/1489>. Acesso em: 05 jun. 2021.

GUY, Gregory; ZILLES, Anna. Sociolinguística Quantitativa: instrumental de análise. Parábola Editorial: São Paulo, 2007.

HENGEVELD, K. Illocution, mood, and modality. In: BOOIJ, G.; LEHMANN, C.; MUGDAN, J. Morphology: a handbook on inflection and word formation. v. 2. Berlin: Mouton de Gruyter, 2004, p.1190-1201.

MANZOTTI, Reginaldo. Batalha espiritual: entre anjos e demônios. Rio de Janeiro: Editora Petra, 2017. 176p.

MANZOTTI, Reginaldo. Combate espiritual: no dia a dia. Rio de Janeiro: Editora Petra, 2018. 200 p. 
MANZOTTI, Reginaldo. O Poder Oculto. Rio de Janeiro: Petra, 2019. 176 p.

MANZOTTI, Reginaldo. As muralhas vão cair: como fazer um Cerco de Jericó em sua vida. Rio de Janeiro: Editora Petra, 2020. 176p.

NEVES, M. H. M. Gramática funcional: interação, discurso e texto. São Paulo: Contexto, 2018.

OLIVEIRA, André Silva. Modalidade volitiva em lingua espanbola nos discursos do Papa Francisco em viagem apostólica. 2017. 310 f. Dissertação (Mestrado em Linguística) - Programa de PósGraduação em Linguística, Universidade Federal do Ceará (UFC), Fortaleza, 2017.

OLIVEIRA, André Silva. A modalidade volitiva no discurso de posse de Jair Bolsonaro. Revista Dominios da Linguagem, v. 13, n. 3, 2019, p. 1211-1227. Disponível em: $<$ http://www.seer.ufu.br/index.php/dominiosdelinguagem/article/view/46966/2731 6>. Acesso em: 15 abr. 2020.

OLIVEIRA, André Silva; PRATA, Nadja Paulino Pessoa. Aspectos semânticos e morfossintáticos da modalidade volitiva nos discursos de investidura de Rodríguez Zapatero. Revista Entrepalauras, Fortaleza, v. 8, 2018a, p. 153-168. Disponível em: $<$ http://www.entrepalavras.ufc.br/revista/index.php/Revista/article/view/1190/540>. Acesso em: 15 abr. 2020.

OLIVEIRA, André Silva; PRATA, Nadja Paulino Pessoa. As formas de expressão da modalidade volitiva nos discursos de Papa Francisco em viagem apostólica. Revista do Gelne, v. 20, n. 2, 2018b, p. 83-97. Disponível em: <https://periodicos.ufrn.br/gelne/article/view/14243/10975>. Acesso em: 15 abr. 2020.

PEZATTI, Erotilde Goreti. GDF: uma Teoria Gramatical ou uma Teoria do Uso? Guavira Letras, v. 12, n. 1, 2011, p. 25-35. Disponível em: <http://www.pgletras.ufms.br/revistaguavira/revista_online.htm\#r12>. Acesso em: 15 abr. 2020 . 